\title{
Forced Convection Thermal Analysis of Vortex Generator on Fin Stack
}

\author{
Diksha D Nadkarni* and R.R. Arakerimath \\ Mechanical Department, Savitribai Pune University, India \\ Accepted 01 Sept 2016, Available online 02 Sept 2016, Vol.6, No.5 (Oct 2016)
}

\begin{abstract}
The forced air convection for the heat pipe cooling systems has an important role in managing thermal performance of the electronic and mechanical devices. Heat is dissipated from devices hence it is essential to improve the performance of such systems. Hence a heat pipe fin stack on condenser section is a method for such heat dissipated absorption. Also the vortex generators in triangular and rectangular shape are placed on the fins. Triangular vortex generators are formed by placing small pieces of Copper so that they stick out to form an angle. Vortex generators disrupt the thermal boundary growth and enhance heat transfer between fluid and fin surface. The objective is to increase heat transfer rate by varying the inlet temperature and position of vortex generator on fins by thermal analysis and experimentation. The results show that placing the triangular generators on both sides of heat pipe gives better performance and increases heat transfer. The heat transfer enhancement is highest for both sides followed by one side and no vortex generator. Also it was found that the experimental and thermal analysis results almost match each other.
\end{abstract}

Keywords: Heat pipes, heat enhancement, vortex generator, thermal analysis.

\section{Introduction}

Forced convection cooling of the extended surfaces such as heat sinks and heat pipe fin stack is a primary cooling technique used in microelectronics and telecommunication application. The increasing power densities in such areas have made the encouragement to enhance the research to improve heat enhancement methods. Hence using the arrangement of stacking fins one above other by using vortex generators on a heat pipe is a solution to such problem. The performance of heat pipe is important to meet the energy demands, low manufacturing costs motivates to study the enhancement techniques for HVAC, microelectronics, telecommunication. The vortex generator has emerged as a promising technique for enhancing heat rate. The wings like vortices are punched out of the fin or mounted on the fin to generate longitudinal vortices.The vortex generator takes the fluid from underside of wake to swirl around upper side entraining the periphery to center vortices. This will finally result in culminating the thermal boundary layer and heat transfer is enhanced.

The surface area of inflow and outflow is same, but the convective response is nonlinear and net heat transfer enhancement is manifest. G.Biswas, H.Chattopadhyay (Hrishikesh S Kulkarni et al 2016 ) The vortex generator in a channel to determine the

*Corresponding author: Diksha D Nadkarni structure of flow and heat transfer characteristics in a rectangular channel with built in delta wing protruding from bottom wall numerically. Predictions are made through numerical solution of complete Navier- Stokes Equation and energy equation. Augmentation of heat transfer between flowing fluid and channel is seen. Effect of punched hole, beneath wing type vortex generator on heat transfer and skin friction characteristics is determined. The influence of the vortex generator angle of attack and Reynolds number showed increase as large as 34\% even at exit of a long channel at an angle of attack $26^{\circ}$.

W.R.Pauley, J.K.Eaton (M.S.Aris et al 2011) Heat transfer and fluid mechanics data are obtained from the turbulent boundary layer with arrays of embedded stream-wise vortices containing the both counterrotating and co-rotating vortex pairs. Arrays caused both large local variation in the heat transfer rate and significant net heat transfer augmentation over large areas. Close proximity of other vortices strongly affects the development vortex arrays by modifying the trajectory that they follow. Vortices turn to produce strong distortion of normal 2-D boundary layer structure, which is due to the secondary flow. When one vortex convects other toward wall, strong boundary layer distortion occurs. The heat transfer is elevated where the secondary flow is directed toward wall and reduced where the secondary flow is directed away from the wall. When adjacent vortices lift their neighbour away from the wall, minimal modification of the heat transfer results. 
Jing HE, Anthony M.Jacobi (2011) Group movement of animals in nature, a new vortex generator array deployed in a $\mathrm{V}$ is proposed in this study, aiming to create constructive interference between vortices and improve VG performance. Its impact on surface convection enhancement is experimentally assessed in a developing channel flow. A large aspect ratio duct of $6 \mathrm{~mm}$ high is constructed to model a single passage of plain fin heat exchangers. The frontal air velocity ranges from 0.9 to $2.5 \mathrm{~m} / \mathrm{s}$, corresponding to Reynolds number range based on channel height of 340 to 940 . The proposed V-array demonstrates superiority to a convectional multi row configuration in that affect a much larger heat transfer area, and the boost effect by the trailing pair is manifest even at relatively small Reynolds number. A two pair $\mathrm{V}$ array deployed at $30^{\circ}$ yields $12-36 \%$ augmentation in the total heat transfer for the current channel flow, and is considered an appropriate design for implementation in prototype heat exchanger.

M.Fiebig, et al (JiinYuh Jang et al 2011)Effect of wing type vortex generators on heat transfer and pressure drop of fin and tube exchanger element was investigated. Local heat transfer was measured by liquid crystal thermography on the fin in the Reynolds number range of 600-2700. Flow losses were estimated from the measured pressure drop of an element. Delta wings were used as vortex generators. 4 fin and tube configuration were tested an inlineand a staggered arrangement, each with plain fins and with finsa pair of vortex generators behind each tube. For inline tube arrangement the vortex generators increase the heat transfer by $55-65 \%$ with a corresponding increase of $20-45 \%$ in the apparent friction factor. Results indicate that vortex generators have the potential to reduce considerably the size and mass of heat exchanger for a given heat load.

M.C.Gentry, A.M.Jacobi (W.R.Pauley, J.K.Eaton, 1994) Delta wings placed at the leading edge of a flat plate, stream-wise vortices are generated that modify the flow, the same wings are also used to modify a developing channel flow. Local and average measurements of convection coefficients are obtained using naphthalene sublimation, and the structure of vortices is studied using flow visualization and vortex strength measurements. The pressure drops penalty associated with the heat transfer enhancement of the channel flow is investigated. In regions where vortex induces a surface normal inflow the local heat transfer coefficients are found to increase by as much as $300 \%$ over the baseline flow, depending on the vortex strength and location relative to boundary layer. Vortex strength increases with Reynolds number, wing aspect ratio and wing angle of attack, and vortex strength decreases as vortex carried downstream.

M.S.Aris, et al(Biswas G., Chattopadhyay H. 1999) Forced air convection heat pipe cooling is considered. The excess heat dissipated is encountered by stacking fins on condenser section of heat pipe and experimenting. Also use of punched, adhered protrusions and the effect is observed. The results from all the protrusion arrangement was noted down and by using the CFD software analysis the results were validated. The results matched the before results and both the results taken complimented each other.

Martin Fiebig, et al(SaffaRiffat and Xiaoli Ma 2016) Triangular and rectangular protrusion by punching the small pieces out from fin and stucking out they formed angle of attackwith main flow direction. Effects by single vortex generator on the flow losses, structure and heat transfer is evaluated. Vortex generator geometry, angle of attack, Reynolds number was varied. It was found that delta wings gave best results than delta winglets and rectangular winglets. A.D.Sommers, A.M.Jacobi (Martin Fiebig et al 1991) Commercial refrigeration system frost forms on the air side surface. Frost tolerant design typically employ large fin spacing to delay defrost cycle. On air side the performance is limited. Longitudinal vortex generation is prove and effective technique for thinning the thermal boundary layer and enhancing heat transfer but efficacy not known. They have taken readings and found that heat transfer coefficient range from 33-53 $\mathrm{Wm}^{2} \mathrm{k}^{-1}$.

T.M.Liou, et al(A.D.Sommers, A.M. Jacobi 2005) Local Nusselt number distribution, in a channel having various configuration of vortex generator. Flow pattern and friction factors measured by Doppler velocitymeter and pressure transducer respectively.12 single different vortex generators used to check heat transfer and friction factor. Also differences in fluid flow and heat transfer between single vortex generator and array are alsoaddressed. It was found that I and delta wing gave good thermal performance among all.

JiinYuh Jang, et al(M Fiebig et al 1993) they carried numerical analysis to study the thermal hydraulic characteristics of 3-d laminar inline and staggered plate fin and tube heat exchangers. With VG mounted behind the tube. Vg span angle, VG transverse location investigated. Area reduction and the different internal factors effects was also investigated. Results showed maximum area reduction for inline and staggered is $14.9-25.5 \%$ and $7.9-13.6 \%$ respectively.

\section{Experimental set-up}

Figure1 shows the schematic diagram of the wind tunnel used in the study. Air is used as working fluid. The main components of the systems were the air supply, instrumentations and data acquisition systems, test section. The wind tunnel system was designed to suck room air over the finned side of the heat exchangers by a $15 \mathrm{KW}$ centrifugal fan. The speed of the fan could be adjusted by a frequency drive of motor. The tunnel has a rectangular duct $300 \mathrm{X} 300 \mathrm{X}$ $1000 \mathrm{~mm}$ in cross-section. To minimize heat loss to the surroundings, the tunnel surface was insulated with an $8 \mathrm{~mm}$ thick acrylic sheet. The inlet and exit temperature across the air side of the test section is measured by two thermocouple meshes. The inlet measuring mesh consists of eight thermocouples while 
the exit mesh contains sixteen thermocouples. These thermocouples were pre-calibrated which have an accuracy of $0.1{ }^{\circ} \mathrm{C}$. The measuring points were located at positions as described in the ASHRAE standard. These data signals were individually recorded and then averaged. The air pressure drop across the heat exchangersand the nozzles were, respectively, measured by precisiondifferential pressure transducers, whose accuracies were $0.4 \%$ and $0.25 \%$. Air was driven by a 3.0 HP frequency adjusted axial blower from a wind tunnel within a test section. The test section was constructed by using a commercialflexi-glass plate, $8 \mathrm{~mm}$ thick. The dimension of the testsection was $300 \mathrm{~cm}$ (width), $300 \mathrm{~cm}$ (height) and $1000 \mathrm{~cm}$ (length). The schematic diagram of the plain fin and heat pipe is shown in fig. 3 which has 2 round pipes placed as shown. The heat pipe outside diameter $D_{c}$ is $15 \mathrm{~mm}$, fin pitch is $3 \mathrm{~mm}$, fin thickness 1 $\mathrm{mm}$. Air flow direction length is $43.3 \mathrm{~mm}$ and wave amplitude is $1.5 \mathrm{~mm}$ transverse pitch is $25 \mathrm{~mm}$ and longitudinal pitch is $21.7 \mathrm{~mm}$.Material selection is most important parameter for fin and vortex generator. Copper and aluminum fins are commonlyused. Generally fins are made from aluminum. Aluminum 1100 have strong corrosion resistance. They are sensitive to high temperature ranging $200-250^{\circ} \mathrm{C}$. It have excellent forming characteristics. It contains $99 \%$ aluminum and $0.12 \%$ copper. The protrusions are on the fins of different sizes. It will be triangles with base as $4.2 \mathrm{~mm}, 10.5 \mathrm{~mm}$, chord as $8.4 \mathrm{~mm}, 21 \mathrm{~mm}$ and aspect ratio as 1 and angle of attack as $55^{\circ}$.

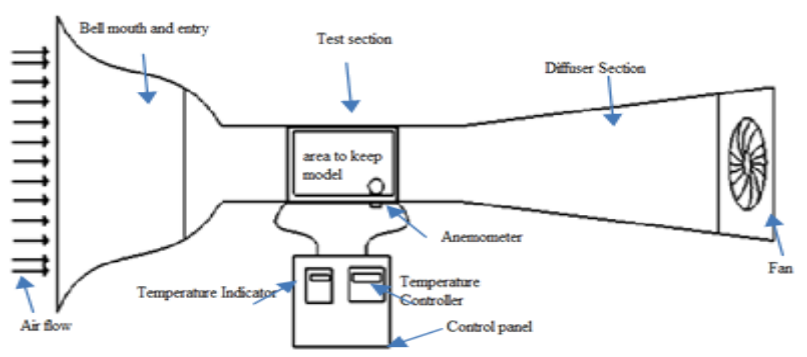

Fig.1 Schematic Diagram of the Wind Tunnel

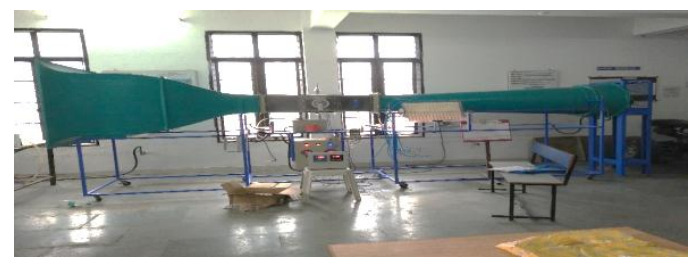

Fig.2 Experimental Setup

\section{Thermal analysis}

The thermal analysis for the 3 models has been taken. The thermal analysis is done with steady thermal condition. The boundary conditions applied are a constant for all the models with a temperature as 60 , 70,75 for the heat pipe and the convection with all standard air properties. The temperature distribution for all the 3 models are tested and it is found that addition of heat protrusions increases the heat flux for the system. Here during the analysis the material selected is copper. The standard properties of copper are selected by default as the material is selected. The boundary condition is $200^{\circ} \mathrm{C}$ given to heat pipe. The temperature is constant. Then the entire system is given convection with steady state and standard values of air. Theproblems are solved and the results of all the models heat flux is obtained.

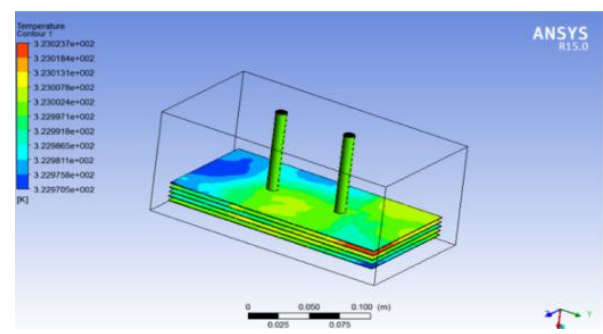

Fig.3 Temperature distribution for no VG

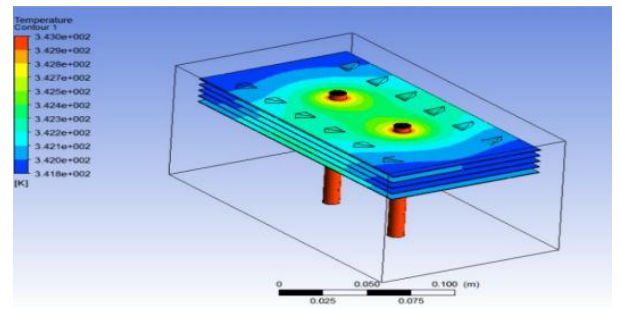

Fig.4 Temperature distribution for Triangular Vg

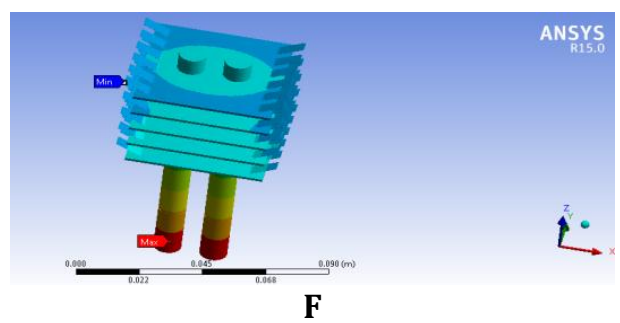

Fig.5 Temperature distribution for rectangular Vg

\section{Results and Discussion}

Graphs1 represents Nusselt number ratio for different arrangements. The ratio for all the models decreases with increase in Reynolds number and heater temperature. The highest ratio obtained is for model with 2 side triangular i.e. 5.32 and that for the lowest is 2.15 that means the turbulence created due to VG has limitation of distance of placing inserts.

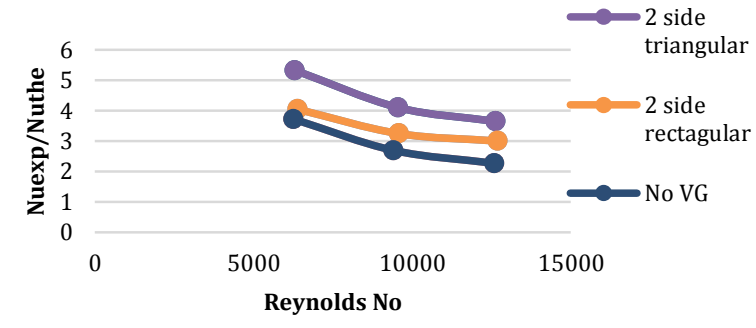

Graph 1. Nu/Nuthe Vs. Re 


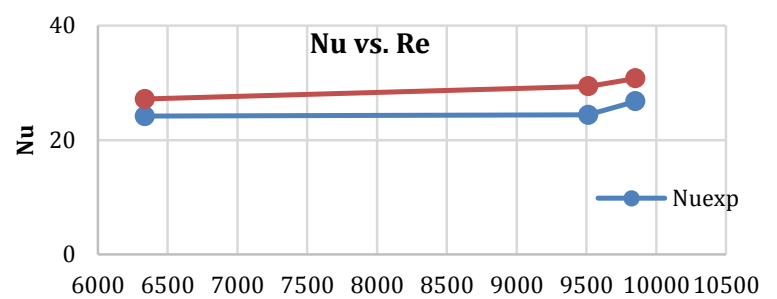

Re

Graph 2. Nu Vs. Re

Graph gives relation between Nusselt number and Reynolds number it shows that as it is directly proportional to each other as Reynolds number increases Nusselt number increases and here shown two lines consists of experimental result and thermal analysis result with $13 \%$ average variation for 2 side triangular VG with AOA 25 degree.

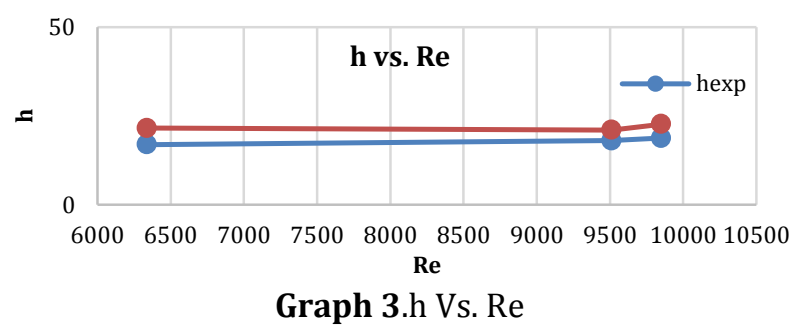

Graph gives relation between heat transfer rate and Reynolds number it shows that as it is directly proportional to each other as Reynolds number increases heat transfer rate increases and here shown two lines consists of experimental result and thermal analysis result with $15 \%$ average variation for 2 side triangular VG with AOA 25 degree.

\section{Conclusion}

The conclusions that can be drawn from the work that is carried out are as given below. The results obtained are nearly equal to the set objectives. Basically the main conclusion that can be derived is that the set goals are achieved and hence the work carried out was successful even after certain drawbacks and problems that occurred during the working period of the manufacturing and experimentation.

Shapes of the vortex generators have impact on the heat transfer as well as the Nusselt number. The observations show that the results obtained are maximum when the model with both side triangular VG functions better than other systems.Triangular shape is the best shape for enhancing heat transfer and the model without VG gives minimum heat transfer in the present work.

Heat transfer for 2 side triangular VG is enhanced 10-12\% more than the plain fin stack. Also the value of Nusselt number increases from $8.3 \%$ to $20.4 \%$ as angle of attack increases from $20^{\circ}-30^{\circ}$.

As the Reynolds number changes from 6600 to 12430 , the value of Nusselt number increases from $8.3 \%$ to $26.03 \%$ for $\mathrm{AOA}=20^{\circ}$, from $19.2 \%$ to $37.9 \%$ for $\mathrm{AOA}=25^{\circ}$ and from $20.4 \%$ to $46.9 \%$ for $\mathrm{AOA}=30^{\circ}$.
The heat transfer enhancement decreases when the rectangular/triangular wings are moved away from the inlet of the duct. Highest heat transfer enhancement occurs for the triangle VG on both sides.

The results of experimental when compared with the results of thermal analysis an average of 18-20\% difference was obtained for the Nusselt number and heat transfer coefficient. The temperature distribution of the models shows that the upper most fin has the lowest temperature. Hence adding VG helps in increasing the heat transfer rate.

\section{References}

Biswas G., Chattopadhyay H., (1992), Heat transfer in a channel with built in wing type vortex generators, Internation Journal of Heat and Mass Transfer, Vol.35, No. 4, pp. 803-814.

Pauley W.R., Eaton J.K., (1994), The Effect of Embedded Longitudinal Vortex Arrays on Turbulent Boundary Layer Heat Transfer, ASME, Vol.116 pp. 871-879.

Jing HE, Jacobi Anthony M. (2010), Air side heat transfer enhancement by a $\mathrm{v}$ formation delta winglet array in a developing channel flow, International Refrigeration and Air conditioning conference at Purdue, July 12-15.

M Fiebig, A.Valencia, Mitra N.K., (1993), Wing type vortex generators for fin tube heat exchangers, Experimental thermal and science; 7; pp. 287-295.

Gentry M.C., Jacobi A.M., Heat Transfer Enhancement by delta wing generated tip vortices in flatplate and developing channel flows. ASME (2002), Vol. 124, pp. 1158-1168.

Fiebig Martin, Peter Kallweit, Mitra Nimai Stefan Tiggelbeck (1991), Heat transfer Enhancement and Drag by longitudinal vortex generator in channel flow, Experimental thermal and science; 4; pp. 103-114.

A.D.Sommers, A.M. Jacobi (2005), Air side heat transfer enhancement of a refrigerator evaporator using vortex generation, International journal of refrigeration $28 \mathrm{pp} .1006$ 1017.

JiinYuh Jang, Ling Fang Hsu, Jin Sheng Leu, Optimisation of the span angle and location of vortex generator in a plate-fin and tube heat exchanger,(2013),International journal of heat and mass transfer 67 pp. $432-444$.

SaffaRiffat and Xiaoli Ma (April 2016), Recent developments in heat pipe technology and applications: a review, Internationa Journal of Low Carbon Technologies 2/2, , pp. 162-177.

M.S.Aris, R.McGlen, I.Owen, C.J.Sutcliffe (2011), An experimental investigation into the deployment of 3-D, finned wing and shape memory alloy vortex generators in a forced air convection heat pipe fin stack, Applied Thermal Engineering 31, pp. 2230-2240.

Kulkarni Hrishikesh S, Kore Sandeep S., Experimental Investigation of Heat Transfer Enhancement by Longitudinal Rectangular Vortex Generator, International Journal of Innovative Research in Advanced Engineering, volume 1 issue 8, ISSN: 2349-2163.

T.M.Liou, C.Chen, T.W.Tsai (May 2000), Heat transfer and fluid flow in a square duct with 12 different shaped vortex generators, ASME, Vol. 122 pp. 327-335.

Elsherbini A.I., Jacobi A.M. (October 2002), The thermalhydraulic impact of delta wing vortex generator on the performance of a plain fin and tube heat exchanger, HVAC\&R, Vol. 8 No.4.

Jacobi A.M., Shah R.K., Air side flow and heat transfer in compact heat exchanger: A discussion of Enhancement Mechanisms, Heat Transfer Eng.19, pp. 29-41.

Fiebig, Vortices, Generators and Heat transfer, Chem. Eng. Res. Des., 76(A2), pp. 108-123.

Dr. Gupta Anirudh, Uniyal Mayank (July-Aug 2012), Review of Heat Transfer Augmentation through Different Passive Intensifier Methods,IOSR Journal of Mechanical and Civil Engineering ISSN: 2278-1684 Volume 1, Issue 4, pp. 14-21. 